\title{
AN AUTORADIOGRAPHIC STUDY OF THE PRENATAL DEVELOPMENT OF BENZODIAZEPINE-BINDING SITES IN RAT BRAIN $^{1}$
}

\author{
MARGRET SCHLUMPF, ${ }^{2}$ J. GRAYSON RICHARDS, ${ }^{*}$ WALTER LICHTENSTEIGER, AND \\ HANNS MÖHLER*
}

Institute of Pharmacology, University of Zürich, Zürich, Switzerland, and *Pharmaceutical Research Department, F. Hoffmann-La Roche \& Co., Ltd., Basel, Switzerland

Keceived December 6, 1982; Revised February 17, 1983; Accepted February 22, 1983

\begin{abstract}
The regional development of benzodiazepine-binding sites in fetal brain was studied by autoradiography. Cryostat sections through the brains of fetuses from time-pregnant rats were incubated either with $\left[{ }^{3} \mathrm{H}\right]$ flunitrazepam or with the specific benzodiazepine antagonist $\left[{ }^{3} \mathrm{H}\right] \mathrm{RO} 15-1788$. The specificity of radioligand binding was checked by co-incubation with an excess of nonradioactive antagonist or clonazepam, respectively.

Labeling with either agonist or antagonist revealed a similar developmental pattern of binding sites. Specific binding was first detected on gestational day (GD) 14 in the spinal cord and lower brainstem. Between GD 14 and GD 15, labeling spread throughout the lower brainstem, mesencephalon, and parts of the diencephalon, with higher densities in ventral areas. Matrix zones remained unlabeled. On GD 16, binding was present in the developing caudate putamen, the olfactory bulb, and the frontoventral parts of the neocortex. Binding sites had spread over the remaining neocortex by GD 21 and increased in density in di- and telencephalic areas. At earlier stages of development, neocortical binding sites were restricted to the superficial (GD 16 and 18) and deep (GD 18) layers above and below the cortical plate; the latter was unlabeled. By GD 21, binding sites also occurred in the cortical plate with an inside-out density gradient. By this time, layer I exhibited the highest density of silver grains.

Thus, our autoradiographic data reveal a distinct ontogenetic pattern of benzodiazepine-binding sites. The general caudorostral gradient, as well as the development in individual brain regions such as neocortex, appears to be linked with cell differentiation, though not necessarily with synaptogenesis. The capacity of the fetal brain to bind benzodiazepines specifically may help to explain the drug effects described in offspring of benzodiazepine-treated dams. Our observations suggest that different brain structures become targets for the action of this class of drugs at different stages of prenatal development.
\end{abstract}

\footnotetext{
Alterations in the behavior of offspring after prenatal exposure to psychoactive substances are of growing interest. Treatment of pregnant rats with high doses of benzodiazepines (BDZs) has been reported to affect the development of locomotor activity and of the acoustic startle reflex in the progeny (Kellogg et al., 1980, 1983). These changes do not appear to be a consequence of the presence of drug remaining in brain tissue (Kellogg et al.,

${ }^{1}$ We thank Mrs. V. Haller and Mrs. Z. Bleuel for excellent technical assistance. The study was supported by Swiss National Science Foundation Grants 3.547-0.79 and 3.170-0.81.

${ }^{2}$ l'o whom correspondence should be addressed, at Institute of Pharmacology, University of Zürich, Gloriastrasse 32, CH-8006 Zürich, Switzerland.
}

1983; Simmons et al., 1983). Early postnatal effects have also been reported in human neonates after prenatal exposure to high doses of BDZ (Cree et al., 1973; Speight, 1977; American Academy of Pediatrics: Committee on Drugs, 1982; Kanto, 1982).

Biochemically, BDZ-binding sites are detectable 8 days before birth in rat brain homogenates (Braestrup and Nielsen, 1978; Mallorga et al., 1980; Regan et al., 1980); they reach almost maximal levels just 1 week after birth (Candy and Martin, 1979). However, these studies did not reveal the precise regional distribution of BDZ-binding sites in the brain during prenatal development. Therefore, autoradiographic investigations were carried out to resolve this problem. $\left[{ }^{3} \mathrm{H}\right]$ Flunitrazepam and $\left[{ }^{3} \mathrm{H}\right]$ Ro 15-1788, a BDZ agonist and antagonist, respectively, 
were used as radioligands. A recent study (Richards et al., 1982) has revealed that the agonist has an affinity for both receptor and acceptor sites in the brain. The latter are binding sites unrelated to the central effects of BDZ tranquilizers; they are found in the ependyma and choroid plexus and represent part of the BDZ-binding sites in the olfactory bulb. At these sites, $\left[{ }^{3} \mathrm{H}\right]$ flunitrazepam is displaced by Ro $5-4864$, a nontranquilizing $\mathrm{BDZ}$ that does not interact with the $\mathrm{BDZ}$ receptor. The antagonist (Ro 15-1788) is a ligand only for the receptor-binding sites. $\mathrm{BDZ}$ receptors have been localized in nerve terminal regions, some of which are GABAergic (Möhler et al., $1980,1981)$.

Our study revealed marked differences between individual brain regions. We found a sequential development of $\mathrm{BDZ}$-binding sites in relation to the maturation of brain structures.

\section{Materials and Methods}

Animals and tissue preparation. Time-pregnant females were bred in our colony of Zivic Miller/SpragueDawley rats. The animals were kept under a constant light/dark cycle (lights on: 6:00 A.M. to 8:00 P.M.) at 22 $\pm 1^{\circ} \mathrm{C}$ and had free access to food (NAFAG 850) and water. Females were exposed to experienced males for a limited period of time $(2 \mathrm{hr})$ after the onset of the dark period. Sperm-positive females were considered as pregnant. They were separated from the rest of the breeding colony (two per cage) and their weight gain was observed. Twenty-four hours after the 2-hr mating period was considered as gestational day (GD) 1. For the receptorbinding studies, pregnant animals were taken at different gestational days (GD 14 to 21) and anesthetized with chloral hydrate $(700 \mathrm{mg} / \mathrm{kg}$, s.c.). The uterus was exposed and the fetuses were separated from the fetal membranes. They were immobilized, kept on ice, and perfused immediately through the heart with an ice-cold fixative solution containing $0.1 \%$ formaldehyde in phosphatebuffered saline; this treatment does not alter the binding of BDZ in adult rat brain (Young and Kuhar, 1980). The perfused whole brains or whole bodies (of early gestational age animals) were quickly frozen in isopentane cooled with liquid nitrogen and stored in liquid nitrogen until cut in the cryostat.

Incubation with radioligands. For the incubation with radiolabeled ligands, $10-\mu \mathrm{m}$ sections of fixed tissue were cut on a cryostat (American Optical Corp.) and thawmounted onto pre-cleaned, gelatin-coated slides. The slides were kept at $-20^{\circ} \mathrm{C}$ for several days or weeks until used, conditions which do not alter the binding characteristics of BDZ. Incubation was carried out with $\left[{ }^{3} \mathrm{H}\right]$ flunitrazepam $\left.\left({ }^{3} \mathrm{H}\right] \mathrm{FNZP} ; 1 \mathrm{nM}\right)$, with or without the BDZ antagonist Ro 15-1788 $(1 \mu \mathrm{M})$, or with $\left[{ }^{3} \mathrm{H}\right] \mathrm{Ro}$ 15$1788(2 \mathrm{nM})$, with or without clonazepam $(1 \mu \mathrm{M})$, at 0 to $4^{\circ} \mathrm{C}$ for $40 \mathrm{~min}$. Then the slides were washed three times in Tris-HCl buffer, dipped into distilled water, dried in dry ice-cooled nitrogen gas, and stored over a desiccant overnight. The slides subsequently were covered with tritium-sensitive sheet film (LKB Ultrofilm) or with emulsion (Ilford K5)-coated coverslips according to the methods of Palacios et al. (1981) and Young and Kuhar (1979), respectively. After an exposure time of 10 to 21 days in Kodak X-Omatic cassettes, the films were developed (Kodak D-19). The sheet film was printed as a negative, and the coverslip preparations, Nissl-stained and remounted with DEPEX, were examined and photographed with darkfield optics.

\section{Results}

The BDZ agonist $\left[{ }^{3} \mathrm{H}\right] \mathrm{FnZP}$, as well as the antagonist $\left[{ }^{3} \mathrm{H}\right] \mathrm{Ro} 15-1788$, was found to bind specifically to fetal rat brain structures during the last third of gestation; i.e., from GD 14. The agonist binding was almost completely displaceable by Ro $15-1788$, while $\left[{ }^{3} \mathrm{H}\right]$ Ro $15-1788$ was completely displaced by addition of clonazepam to the incubation solution (Figs. 21 and 22). Silver grain densities obtained with the agonist appeared to be somewhat higher, especially in tissue of early fetal stages. As in adult rats (Richards et al., 1982), $\left[{ }^{3} \mathrm{H}\right] \mathrm{FNZP}$ but not $\left[{ }^{3} \mathrm{H}\right]$ Ro 15-1788 showed a moderate affinity for the ependyma, choroid plexus, and, during the later stages of gestation, the olfactory nerve layer in the bulb; these binding sites have been called acceptor sites because they are displaced by the nontranquilizing $\mathrm{BDZ}$, Ro 5-4864.

GD 14 (crown-rump length (CRL): $10.9 \mathrm{~mm}$ ). Before GD 14, no specific binding was seen in fetal CNS structures. At this stage, an accumulation of silver grains of low density was observed in $\left[{ }^{3} \mathrm{H}\right] \mathrm{FNZP}$-incubated sections at the level of the upper spinal cord and lower brainstem up to the level of the cerebellar flexure (Figs. 1 and 2). Comparable binding of slightly lower intensity was obtained after incubation with $\left[{ }^{3} \mathrm{H}\right] \mathrm{RO} 15-1788$. Specificity of agonist and antagonist binding was checked by displacement with R015-1788 and clonazepam, respectively. Staining at this stage was not uniformly distributed in the spinal cord and the lower brainstem, but was restricted to marginal and mantle layers of the ventral neural tube.

GD $14^{3 / 4}$ to 15 (CRL: 12.1 to $12.7 \mathrm{~mm}$ ). The most striking progress in the development of $\mathrm{BDZ}$ agonist- and antagonist-binding sites took place in the fetal CNS between GD 14 and GD 15. Within 24 hours at most, cells of large areas of the fetal brain, with the exception of neocortex, acquired the capacity to bind specifically $\mathrm{BDZ}$ agonists and antagonists. Midbrain and ventral diencephalon appeared strongly labeled (Figs. 3 and 4). Weak labeling was also seen in the basal telencephalon, rostral to the preoptic region. At all caudorostral levels from lower brainstem to forebrain, binding was observed mainly in ventral structures. This was especially evident in sagittal sections. At about the level of the diencephalictelencephalic junction, silver grains spread to lateral parts of the diencephalon where, at this stage, the primitive internal capsule is formed by the ascending thalamocortical systems. Labeling was also detected in the basal striatal regions of the GD 15 brain. As a rule, $\mathrm{BDZ}$ binding was never observed in matrix zones, that is, proliferating zones, in sagittal sections through the hypothalamus.

GD 16 (CRL: $15.1 \mathrm{~mm})$. In lower brainstem and mesencephalon, the differences in labeling of the ventral and dorsal parts largely disappeared (Figs. 5 to 7 ). In the ventromedial part of the mesencephalon, where the mesencephalic DA cell complex is expanding rapidly and 

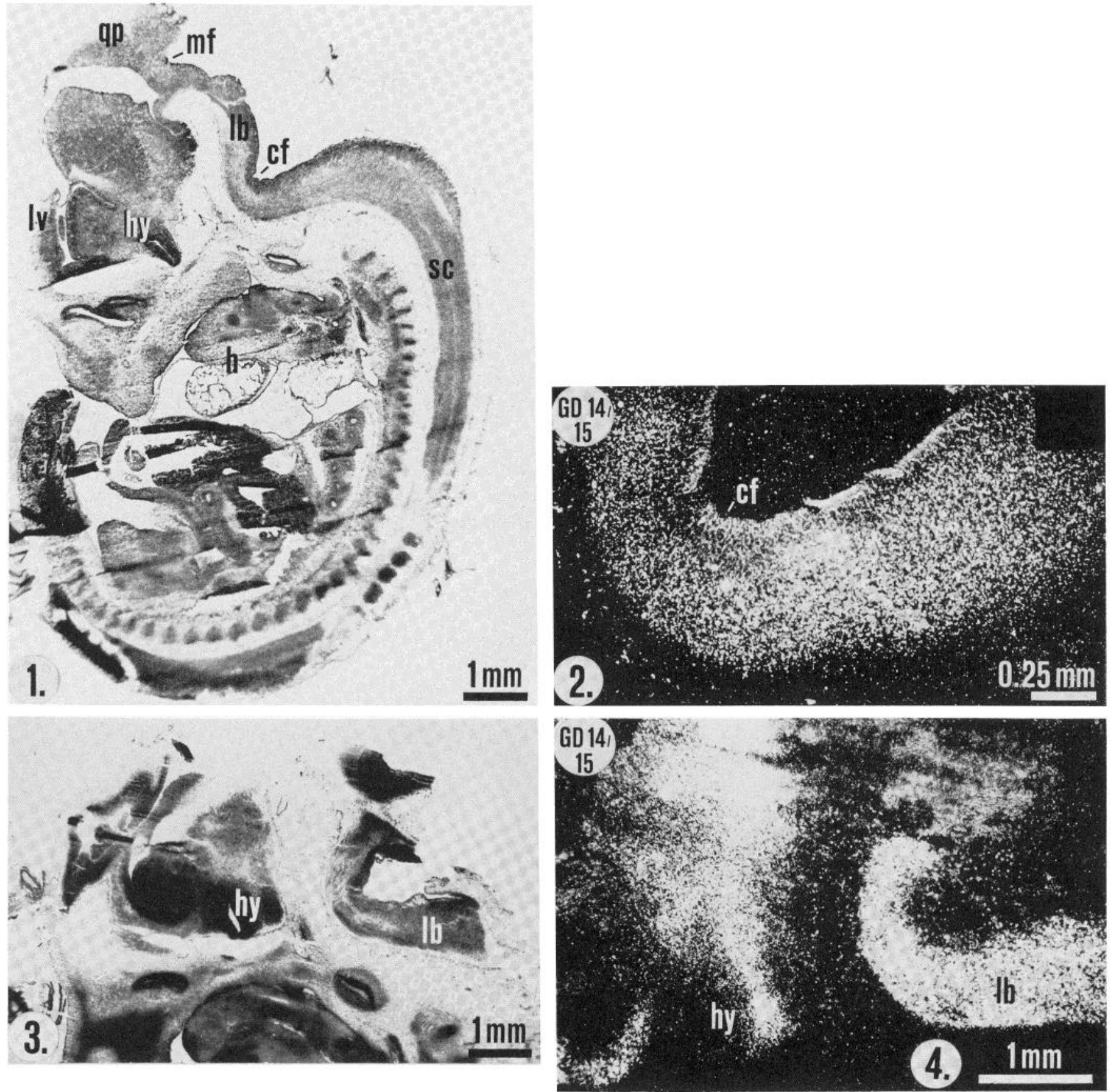

Figure 1. Cresyl violet-stained sagittal section through a whole GD 14 rat fetus showing different brain structures and the fetal heart. $c f$, cerebellar flexure; $h$, heart; $h y$, hypothalamus; $l b$, lower brainstem; $l v$, lateral ventricle; $m f$, mesencephalic flexure; $q p$, quadrigeminal plate; $s c$, spinal cord.

Figure 2. Autoradiographic localization of $\left[{ }^{3} \mathrm{H}\right]$ flunitrazepam (total binding) in a sagittal section of the lower brainstem on GD 14. White areas indicate the presence of the radioligand. $c f$, cerebellar flexure. Darkfield optics.

Figure 3. Cresyl violet-stained sagittal section through a GD 15 rat brain. hy, hypothalamus; $l b$, lower brainstem.

Figure 4. Autoradiographic localization of $\left[{ }^{3} \mathrm{H}\right]$ Ro $15-1788$ (total binding) in a section adjacent to that shown in Figure 3 . On GD 15 , labeling is dense in the lower brainstem $(l b)$ and the posterior hypothalamus (hy). Labeling continues as a band into the preoptic region (lower left). Darkfield optics.

where the ascending catecholamine CA fiber bundle is already very prominent (Schlumpf et al., 1980), the grain density was higher than in the more lateral parts. In the diencephalon, labeling was still concentrated in the ventromedial and ventrolateral parts at all caudocranial levels. The telencephalon contained those brain regions where binding was most recent. Here, a distinct ventrodorsal gradient was observed. In the developing striatal region, binding was absent in the densely packed cells of the proliferating ependymal zone of the lateral ventricle, with only sparse binding in the subependymal layer. The majority of silver grains overlay the developing caudate 


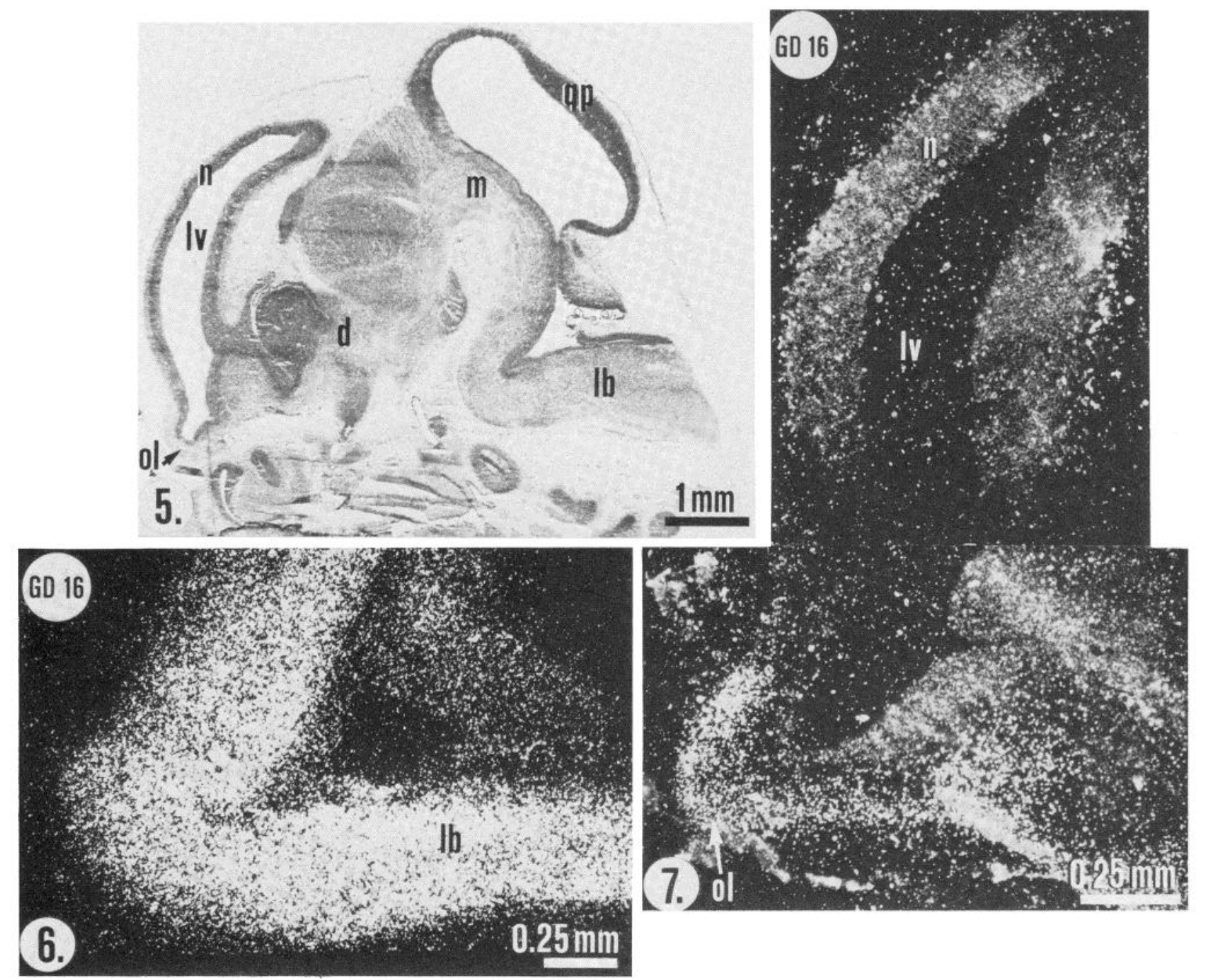

Figure 5. Cresyl violet-stained sagittal section through a GD 16 rat brain. $d$, diencephalon; $l b$, lower brainstem; $l v$, lateral ventricle; $m$, mesencephalon; $n$, neocortex; ol, olfactory bulb; $q p$, quadrigeminal plate.

Figure 6. Autoradiographic localization of $\left[{ }^{3} \mathrm{H}\right]$ flunitrazepam (total binding) in a sagittal section of the lower brainstem at the level of the cerebellar flexure. On GD 16, the labeling in the lower brainstem $(l b)$ is very dense and shows a slight dorsoventral gradient. Darkfield optics.

Figure 7. Autoradiographic localization of $\left[{ }^{3} \mathrm{H}\right] \mathrm{Ro} 15-1788$ (total binding) in a sagittal section adjacent to Figure 5 . Note the dense labeling of the olfactory bulb $(o l)$ and basal telencephalic structures on GD 16, but the virtual absence of binding sites in the neocortex $(n)$, at this time. $l v$, lateral ventricle. Darkfield optics.

putamen (Figs. 8 and 9). An increased density was seen ventrolaterally, in an area where the olfactory tubercule and pyriform cortex will be located.

On GD 16 some labeling was also found in the cell layers of the olfactory bulb (Figs. 5 and 7 ) and, for the first time, in neocortical structures (Figs. 10 and 11). GD 16 marks the date of arrival of the first neuroblasts to form the cortical plate. This event initiates the separation of the primordial plexiform layer into a superficial and a deep cell population. In the neocortex of GD 16, BDZ binding occurred mainly in the frontoventral parts and was restricted to the most superficial cortical layer which is derived from the primordial plexiform layer.

GD 18 (CRL: $20.9 \mathrm{~mm}$ ). Between GD 16 and GD 18 the neocortical rim as seen on sagittal sections is expanding rapidly (Fig. 12). On GD 17 the immature trilami- nated cortical structure (König et al., 1975) is already discernible, becoming clearly evident by GD 18 . The three neocortical layers consist of the subpial layer with horizontally oriented cells, the densely packed, vertically oriented cell layer, and a third layer of larger horizontal neurons just above the intermediate zone. The first neocortical synapses are described for the superficial and deep layers on GD 16. BDZ binding to neocortical structures developed between GD 16 and GD 18 within the immature trilaminated cortex where distinct concentrations of silver grains were observed in the superficial and deep layers (Figs. 13 and 14). Some labelling also occurred within the (intermediate) cortical plate. This pattern stayed the same at all lateromedial levels of the developing neocortex of GD 18. Labeling of the olfactory bulb was greatly increased at this time, compared to GD 

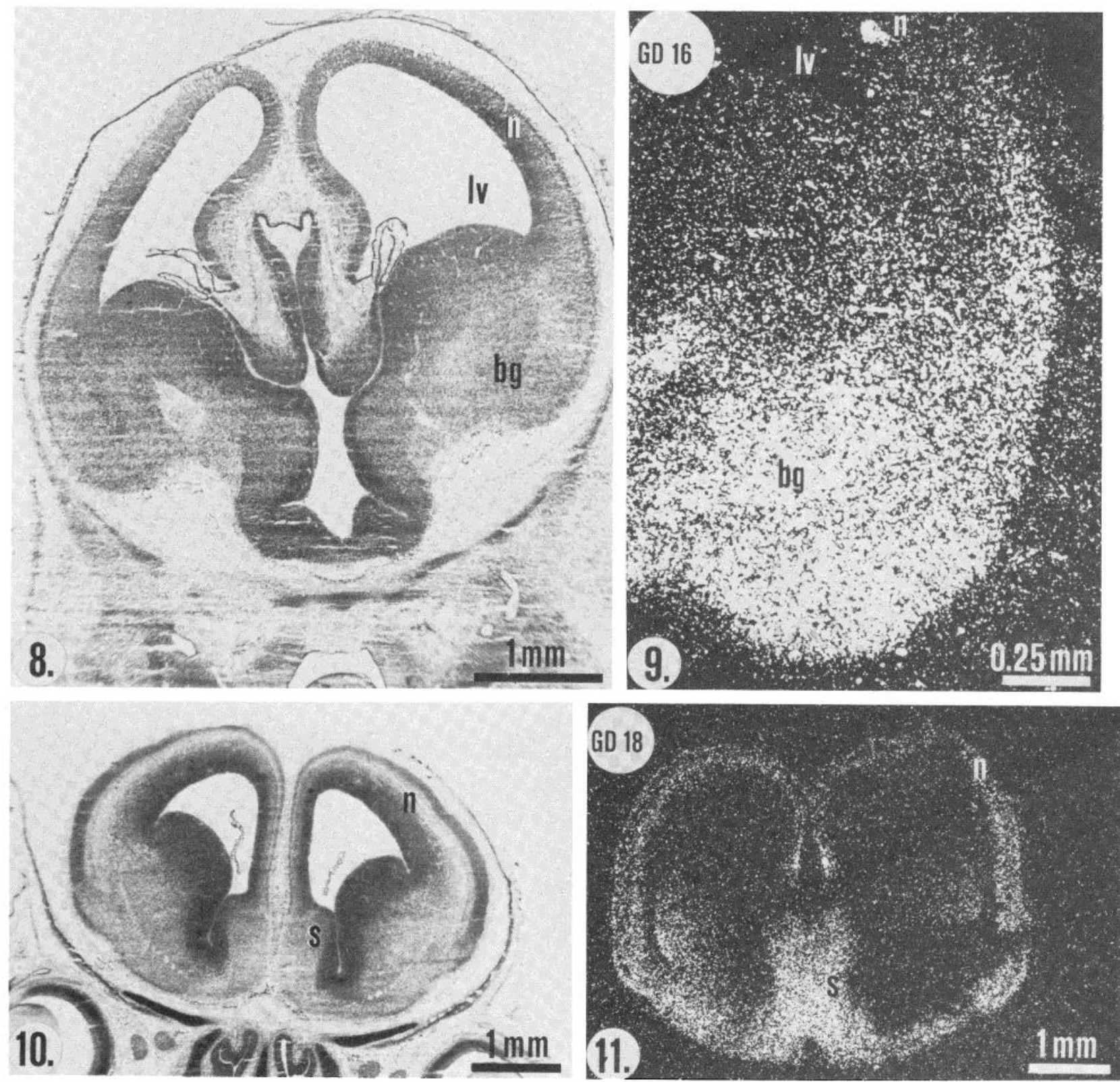

Figure 8. Cresyl violet-stained frontal section through the telencephalon of a GD 16 rat fetus. $b g$, basal ganglia; $l v$, lateral ventricle; $n$, neocortex.

Figure 9. Autoradiographic localization of $\left[{ }^{3} \mathrm{H}\right]$ flunitrazepam (total binding) in a frontal section adjacent to Figure 8 . Note the intense labeling, on GD 16, of the basal ganglia $(b g)$ compared to the neocortex $(n)$. $l v$, lateral ventricle. Darkfield optics.

Figure 10. Cresyl violet-stained frontal section through a GD 18 brain at the level of the septal nuclei $(s)$. $n$, neocortex.

Figure 11. Autoradiographic localization of $\left[{ }^{3} \mathrm{H}\right]$ flunitrazepam (binding in the presence of nonradioactive Ro 5-4864, a ligand specific for peripheral benzodiazepine-binding sites in the brain), in a frontal section adjacent to Figure 10. Note the dense labeling in the septal area $(s)$. In the neocortex $(n)$ the typically bifurcated binding pattern is seen in the prospective layers I and VI. Ultrofilm.

16, the exception being the zone around the olfactory ventricle (Figs. 12 and 13). In the septum, grain densities were slightly higher than in the striatal region (Fig. 15). Labeling in the septal area was concentrated in the medial septal nuclei. BDZ binding in the mesencephalon and lower brainstem (Figs. 13 and 14) was quite uniformly distributed at this developmental stage, although there was still a tendency toward higher grain densities in more ventral structures. No labeling was seen in the matrix and ependymal zones of the GD 18 brain.

$G D 21$ (CRL: $40.9 \mathrm{~mm}$ ). Two days before birth, BDZ binding approached an adult-like pattern in those brain regions known to strongly bind $\mathrm{BDZ}$ in the adult animal. In the adult rat, highest grain densities are observed in the olfactory bulb, neocortex, globus pallidus, superior and inferior colliculi, hippocampus, amygdala, substantia nigra, cerebellum, and dorsal horn of the spinal cord (Young and Kuhar, 1980; Möhler and Richards, 1982). Moderate densities occur in the caudate putamen and brainstem.

The most remarkable development on GD 21 was the pronounced increase in labeling of frontal telencephalic 

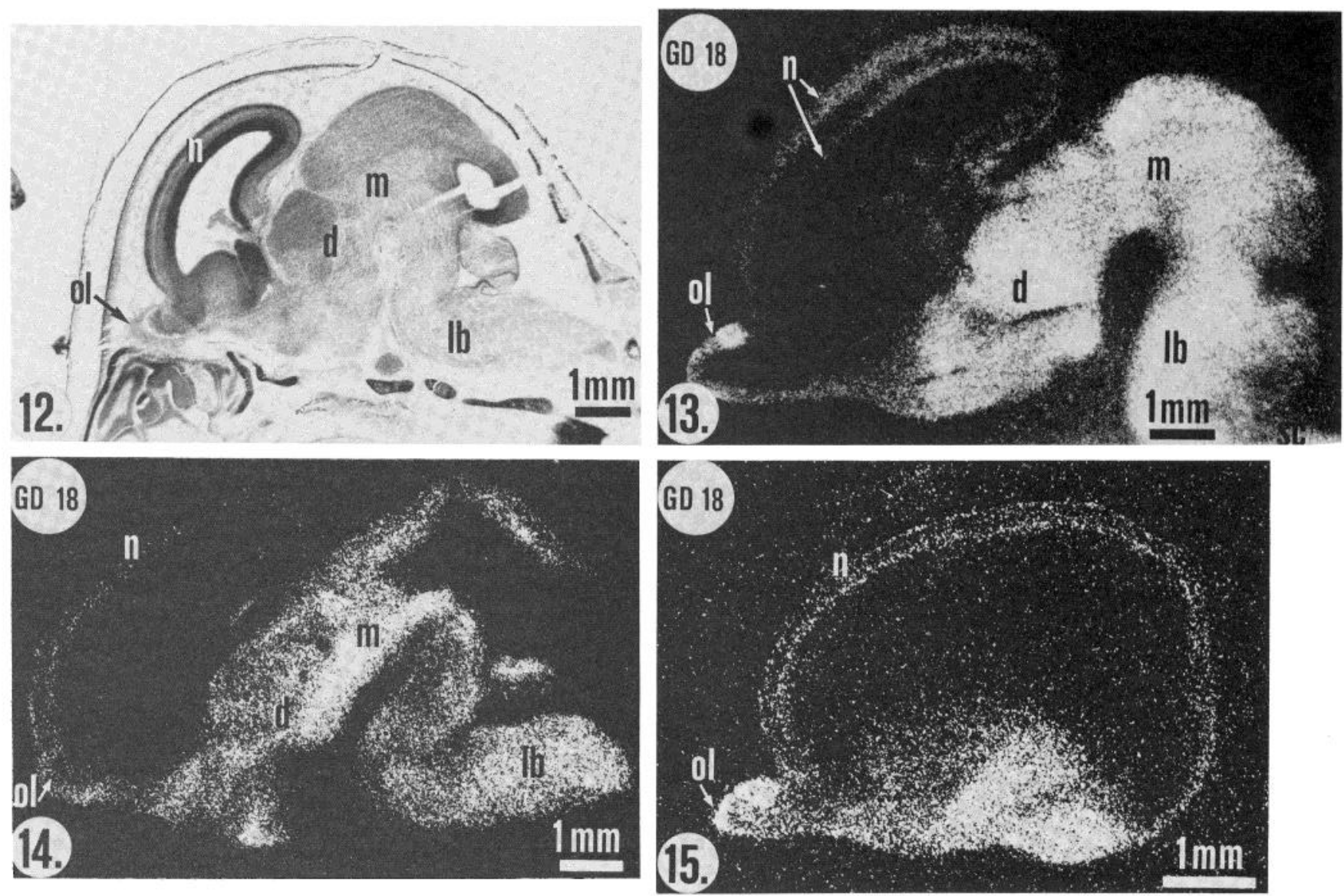

Figure 12. Cresyl violet-stained sagittal section through a GD 18 brain. $d$, diencephalon; $l b$, lower brainstem; $m$, mesencephalon; $n$, neocortex; ol, olfactory bulb.

Figure 13. Autoradiographic localization of $\left[{ }^{3} \mathrm{H}\right] \mathrm{Ro}$ 15-1788 (total binding) in a section adjacent to Figure 12. On GD 18, dense labeling occurs in the lower brainstem $(l b)$, the di- and mesencephalon $(d, m)$, and the olfactory bulb $(o l)$. In the neocortex $(n)$, binding is preferentially located in the prospective layers I and VI. Darkfield optics.

Figure 14. Autoradiographic localization of $\left[{ }^{3} \mathrm{H}\right]$ flunitrazepam (binding in the presence of Ro 5-4864), in a sagittal section at a level medial to that of Figure 13. Here, the dorsoventral gradient of labeling is clearly visible in the di- and mesencephalon $(d, m)$. The neocortex $(n)$ shows the typical bifurcated pattern of binding. $l b$, lower brainstem; ol, olfactory bulb. Ultrofilm.

Figure 15. Autoradiographic localization of $\left[{ }^{3} \mathrm{H}\right]$ flunitrazepam (binding in the presence of Ro 5-4864) in a sagittal section of the lateral forebrain. Binding occurs in the region of the basal ganglia, in the olfactory bulb $(o l)$, and in the neocortex $(n)$, where the prospective layers I and VI are labeled. Ultrofilm.

brain regions, especially the neocortex (Figs. 16 to 18). However, in contrast to the adult brain, labeling in lower brainstem regions remained intense. In the trilaminated neocortex on GD 18, binding was essentially restricted to the superficial and deep layers, sparing the cortical plate. On GD 21, these two layers continued to be strongly labeled. In addition, the deeper part of the cortical plate, which in the meantime had become more differentiated (Raedler et al., 1980), was now also intensely labeled with a distinct gradient from deeper to intermediate zones of the cortical plate. At this stage, numerous BDZ-binding sites were found in the olfactory bulb (Fig. 19). Moreover, the zone of the inner nuclear layer of the retina (Fig. 20), which 3 days earlier showed only few silver grains, was now heavily labeled.

\section{Discussion}

Receptor-mediated effects represent one possible mode of action of drugs on the fetal nervous system, although other types of cellular interaction may also occur. Binding sites for various classes of centrally active drugs become detectable during fetal life; for example, for opiates (Coyle and Pert, 1976; Kent et al., 1982), neuroleptics (Lichtensteiger et al., 1982), $\beta$-adrenergic antagonists (Bruinink et al., 1982), and BDZs (Braestrup and Nielsen, 1978; Mallorga et al., 1980; Regan et al., 1980). Hence, it seems conceivable that some of the behavioral changes noted in the offspring of rats treated with $\mathrm{BDZ}$ during pregnancy resulted from drug actions on $\mathrm{BDZ}$ receptors in fetal brain.

Any attempt to understand the changes in brain function generated by prenatal $\mathrm{BDZ}$ treatment requires precise information on the development of the corresponding binding sites in individual fetal brain regions. Our autoradiographic observations show that central BDZbinding sites develop in a distinct pattern with a general caudorostral gradient, features that are not evident from previous biochemical reports in which no regional analysis of fetal brain was performed. The appearance of binding sites seems to be related to the stage of maturation of individual brain structures.

$\mathrm{BDZ}$ binding was first detected on GD 14, in agreement 

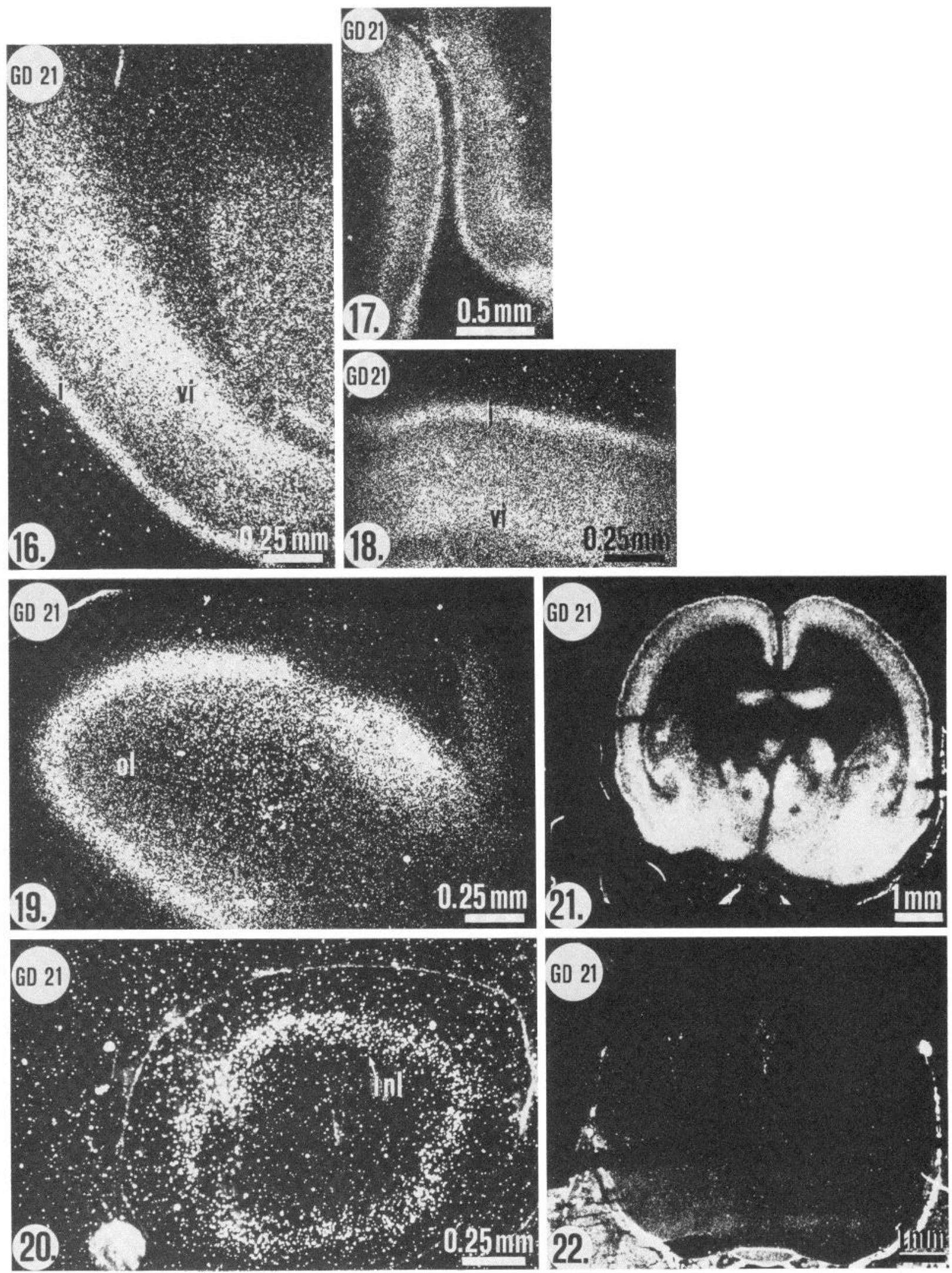

Figures 16 to 18 . Autoradiographic localization of $\left[{ }^{3} \mathrm{H}\right] \mathrm{Ro}$ 15-1788 (total binding) in frontal sections of the frontal neocortex on GD 21. Figures 16 and 18 show part of the frontolateral neocortex, Figure 17 shows part of the frontomedial neocortex. Labeling is very distinct in the prospective layer I. At this developmental stage the cortical plate and the subplate regions are also stained. Within the cortical plate an inside-out gradient is noted, except for layer I. $i$, vi, layers I and VI of cerebral cortex. Darkfield optics. 


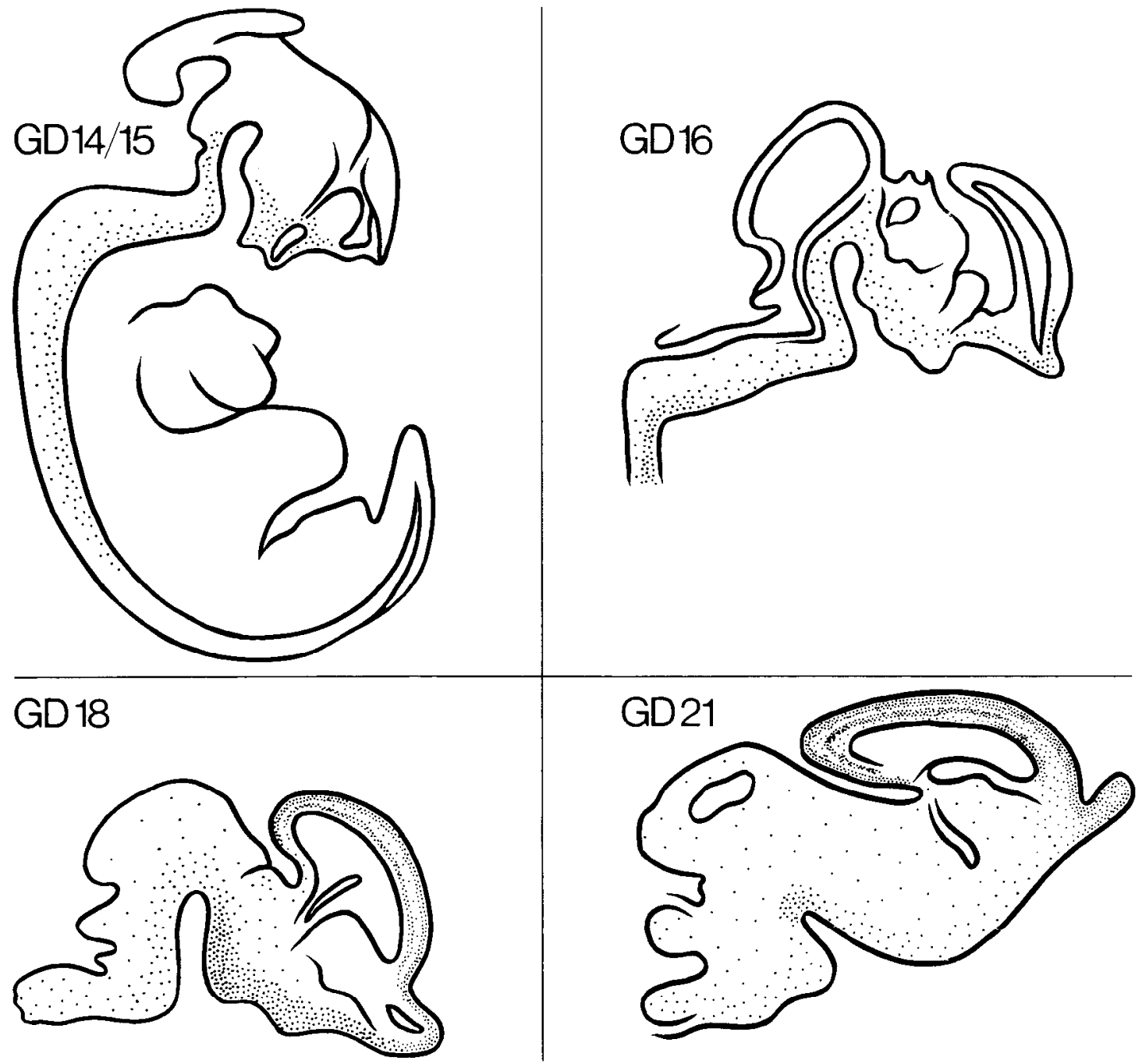

Figure 23. Schematic representation of the distribution of benzodiazepine-binding sites in sagittal sections of fetal rat brain on gestational days (GD) 14/15, 16, 18, and 21.

with the observations of Braestrup and Nielsen (1978). At this stage (Fig. 23), labeling is limited to the spinal cord and lower brainstem, with the highest density in the ventral marginal zone. In studies on mouse brain, this area has been found to be the site of the first synaptic contracts formed (Vaughn et al., 1977). A striking spread of BDZ-binding sites occurs between GD 14 and GD 15, when binding sites appear in diencephalic and basal telencephalic areas. That BDZ-binding sites are situated in differentiating zones is again evident; labeling has never been seen in the matrix zones. The ventrodorsal gradient of neuronal differentiation described, e.g., for the diencephalon (Eitschberger, 1970), is reflected by the higher density of silver grains in ventral areas of this part of the brain as well as of other regions. The link with differentiation processes is especially evident in neocortex. Here, GD 16 marks the onset of the formation of the cortical plate which is accompanied by the separation of the primordial plexiform layer into a superficial and deep cell population. These two layers are phylogenetically older and ontogenetically more advanced than the cortical plate; they contain the first synapses (König et al., 1975). At the GD 16 stage, BDZ binding was found only in the frontoventral part of neocortex, almost exclusively in the superficial layer. Binding sites spread over the remaining neocortical areas by GD 18 , but they remain restricted to the layers above and below the cortical platc. When at a later stage (GD 21), the layers derived from the cortical plate become labeled, the density gradient of silver grains within the cortical plate corresponds

Figure 19. Autoradiographic localization of $\left[{ }^{3} \mathrm{H}\right]$ flunitrazepam (total binding) in a sagittal section through the olfactory bulb $(o l)$ on GD 21, showing the intense binding to the external plexiform layer. Darkfield optics.

Figure 20. Autoradiographic localization of $\left[{ }^{3} \mathrm{H}\right]$ Ro $15-1788$ (total binding) in a frontal section through the eye on GD 21 . Note the intense labeling of the zone of the inner nuclear layer (inl). Darkfield optics.

Figures 21 and 22. Competition experiment (Fig. 21). Autoradiographic localization of $\left[{ }^{3} \mathrm{H}\right] \mathrm{Ro} 15-1788$ (total binding) in a frontal section of a GD 21 forebrain at the level of the anterior diencephalon. This labeling is not visible in an adjacent section (Fig. 22) incubated in addition with $1 \mu \mathrm{M}$ nonradioactive clonazepam. Darkfield optics. 
to the inside-out gradient of cell differentiation (Raedler et al., 1980). Although these observations point to a link between the formation of BDZ-binding sites and nerve cell differentiation, they do not necessarily indicate a relationship to synaptogenesis, despite the fact that BDZ receptors in adult rat brain have been shown to be localized in synaptic regions. In recent studies on postnatal rat cerebellum, the developmental pattern of BDZbinding sites could not be associated with the formation of GABAergic synapses (Palacios and Kuhar, 1982). Moreover, Chisholm and co-workers (1983) have examined the development of $\mathrm{BDZ}$ binding of the triazolopyridazine high and low affinity type in rat cortex, hippocampus, and cerebellum. They observed that the hippocampus, in contrast to the other two regions, contained high affinity binding at birth prior to the periods of dendritic elaboration and synaptogenesis.

The specificity of the sites labeled in our autoradiographs has been assessed for both radiolabeled ligands by displacement studies. It is further corroborated by the observation that the labeling pattern was virtually identical for FNZP and the specific BDZ antagonist Ro 151788 (Darragh et al., 1981; Hunkeler et al., 1981). Biochemical studies indicate that the affinity characteristics of BDZ-binding sites do not noticeably change during ontogeny (Braestrup and Nielsen, 1978; Mallorga et al., 1980; Aldinio et al., 1981). Whether there are changes in the relationship to the GABA receptor remains uncertain. Data on the effect of GABA on BDZ binding during development are contradictory (Palacios et al., 1979; Gallager et al., 1980; Mallorga et al., 1980; Massotti et al., 1980; Regan et al., 1980). Further information may come from studies on ontogenetic patterns of GABAergic binding sites (Coyle and Enna, 1976; Coyle, 1977) which are presently under way.

The mechanism by which BDZs might affect offspring behavior remains unknown. When given to pregnant dams, BDZs do not appear to cause persistent changes in the number or affinity of binding sites (Braestrup et al., 1979; Kellogg et al., 1983). Changes in GABA-induced binding were observed, but only after treatment of dams with very high doses (Massotti et al., 1980). These observations do not seem to exclude a receptor-mediated action of BDZ on fetal brain but, rather, suggest some difference in receptor regulation. The absence of persistent changes in BDZ-binding sites contrasts with data on neuroleptic receptors, which are down-regulated by chronic neuroleptic treatment during pregnancy (Rosengarten and Friedhoff, 1979).

Some developmental effects of BDZ might be mediated by actions on transmitter systems, since it is known that neurotransmitters influence cell proliferation and differentiation. Indeed, Kellogg and co-workers (1982) noted a $30 \%$ reduction in hypothalamic norepinephrine after prenatal $\mathrm{BDZ}$ treatment. The development of ascending catecholamine innervation of the forebrain (Schlumpf et al., 1980) and the developmental pattern of BDZ-binding sites follow a similar pattern and time course.

The distinct developmental pattern of BDZ-binding sites might result in differences in the sensitivity of individual brain regions for this class of drugs at different stages of pregnancy. The relatively strong labeling of structures belonging to sensory systems, such as the eye and the olfactory bulb, should also be emphasized. It remains to be elucidated whether there exist critical periods for the various functional disturbances reported after prenatal BDZ treatment. So far, the drug has always been administered to pregnant rats over periods which comprise all the various developmental stages investigated by the present study. Whether these effects of high doses are mediated by $\mathrm{BDZ}$ receptors or are nonspecific remains to be elucidated.

\section{References}

Aldinio, C., M. Balzano, G. Savoini, A. Leon, and G. Toffano (1981) Ontogeny of ${ }^{3} \mathrm{H}$-diazepam binding sites in different rat brain areas. Dev. Neurosci. 4: 461-466.

American Academy of Pediatrics: Committee on Drugs (1982) Psychotropic drugs in pregnancy and lactation. Pediatrics 69: 241-244.

Braestrup, C., and M. Nielsen (1978) Ontogenetic development of benzodiazepine receptors in the rat brain. Brain Res. 147: 170-173.

Braestrup, C., M. Nielsen, and R. F. Squires (1979) No changes in rat benzodiazepine receptors after withdrawal from continuous treatment with lorazepam and diazepam. Life Sci. 24: 347-350.

Bruinink, A., W. Lichtensteiger, and M. Schlumpf (1982) Characterization and ontogeny of monoaminergic- and spirodecanone-binding sites. In Proceedings of the Fourth Meeting of the European Society for Neurochemistry, Catania: Basic and Clinical Aspects of Molecular Neurobiology, A. M. G. Stella, G. Gombos, G. Benzi, and H. S. Bachelard, eds., p. 457, European Society for Neurochemistry, Catania, Italy.

Candy, J. M., and I. L. Martin (1979) The postnatal development of the benzodiazepine receptor in the cerebral cortex and cerebellum of the rat. J. Neurochem. 32: 655-658.

Chisholm, J., C. K. Kellogg, and A. Lippa (1983) Development of benzodiazepine binding subtypes in three regions of rat brain. Brain Res., in press.

Coyle, J. T. (1977) Biochemical aspects of neurotransmission in the developing brain. Int. Rev. Neurobiol. 20: 65-103.

Coyle, J. T., and S. J. Enna (1976) Neurochemical aspects of the ontogenesis of GABAergic neurons in rat brain. Brain Res. 111: 119-133.

Coyle, J. T., and C. B. Pert (1976) Ontogenetic development of ${ }^{3} \mathrm{H}$-naloxone binding in rat brain. Neuropharmacology 15 : 555-560.

Cree, J. E., J. Meyer, and D. M. Hailey (1973) Diazepam in labour: Its metabolism and effect on the clinical condition and thermogenesis of the newborn. Br. Med. J. 4: 251-255.

Darragh, A., M. Scully, R. Lambe, I. Brick, C. O'Boyle, and W. Downie (1981) Investigation in man of the efficacy of a benzodiazepine antagonist: Ro 15-1788. Lancet 6: 8-10.

Eitschberger, E. (1970) Entwicklung und Chemodifferenzierung des Thalamus der Ratte. Ergeb. Anat. Entwicklungsgesch. 42: 7-75.

Gallager, D. W., P. Mallorga, J. W. Thomas, and J. F. Tallman (1980) GABA-benzodiazepine interactions: Physiological, pharmacological and developmental aspects. Fed. Proc. 39: 3043-3049.

Hunkeler, W., H. Möhler, L. Pieri, P. Polc, E. P. Bonetti, R. Cumin, R. Schaffner, and W. Haefely (1981) Selective antagonists of benzodiazepines. Nature 290: 514-516.

Kanto, J. H. (1982) Use of benzodiazepines during pregnancy, labour and lactation, with particular reference to pharmacokinetic considerations. Drugs 23: 354-380.

Kellogg, C., D. Tervo, J. Ison, T. Parisi, and R. K. Miller (1980) Prenatal exposure to diazepam alters behavioral development in rats. Science 207: 205-207.

Kellogg, C., J. Chisholm, R. D. Simmons, J. R. Ison, and R. K. 
Miller (1983) Neural and behavioral consequences of prenatal exposure to diazepam. In Drugs and Hormones in Brain Development, M. Schlumpf and W. Lichtensteiger, eds., S. Karger, $\Lambda \mathrm{G}$, Basel, in press.

Kent, J. L., C. B. Pert, and M. Herkenham (1982) Ontogeny of opiate receptors in rat forebrain: Visualization by in vitro autoradiography. Dev. Brain Res. 2: 487-504.

König, N., G. Roch, and R. Marty (1975) The onset of synaptogenesis in rat temporal cortex. Anat. Embryol. 148: 73-87.

Lichtensteiger, W., M. Schlumpf, M. D. Davis, A. Bruinink, and U. Otten (1982) Neuroendocrinology of dopamine and noradrenaline systems in early development. Adv. Biosci. 37: 313-325.

Mallorga, P., M. Hamburg, J. Tallman, and D. Gallager (1980) Ontogenetic changes in GABA modulation of brain benzodiazepine binding. Neuropharmacology 19: 405-408.

Massotti, M., F. R. Alleva, T. Balazs, and A. Guidotti (1980) GABA and benzodiazepine receptors in the offspring of dams receiving diazepam: Ontogenetic studies. Neuropharmacology 19: 951-956.

Möhler, H., and J. G. Richards (1982) Anxiolytic receptor sites. In Drug Receptors: Neurochemical, Behavioral and Clinical Perspectives, J. B. Malick, S. J. Enna, and H. I. Yamamura, eds., pp. 15-40, Raven Press, New York.

Möhler, H., M. K. Battersby, and J. G. Richards (1980) Benzodiazepine receptor protein identified and visualized in brain tissuc by a photoaffinity label. Proc. Natl. Acad. Sci. U. S. A. 77: 1666-1670.

Möhler, H., J. G. Richards, and J. -Y. Wu (1981) Autoradiographic localization of benzodiazepine receptors in immunocytochemically identified $\gamma$-aminobutyrergic synapses. Proc. Natl. Acad. Sci. U. S. A. 78: 1935-1938.

Palacios, J. M., and M. Kuhar (1982) Ontogeny of high affinity GABA and benzodiazepine receptors in the rat cerebellum: An autoradiographic study. Dev. Brain Res. 2: 531-539.

Palacios, J. M., D. L. Niehoff, and M. J. Kuhar (1979) Ontogeny of GABA and benzodiazepine receptors: Fffects of Triton X-
100 and muscimol. Brain Res. 179: 390-395.

Palacios, J. M., D. L. Niehoff, and M. J. Kuhar (1981) Receptor autoradiography with ${ }^{3} \mathrm{H}$-sensitive film: Potential for computerized densitometry. Neurosei. Lett. 25: 101-106.

Raedler, E., A. Raedler, and S. Feldhaus (1980) Dynamical aspects of neocortical histogenesis in the rat. Anat. Embryol. 158: 253-269.

Regan, J. W., W. R. Roeske, and H. I. Yamamura (1980) The benzodiazepine receptor: Its development and its modulation by $\gamma$-aminobutyric acid. J. Pharmacol. Exp. Ther. 212: 137143.

Richards, J. G., H. Möhler, and W. Haefely (1982) Benzodiazepine binding sites: Receptors or acceptors? Trends Pharmacol. Sci. 3: 233-235.

Rosengarten, H., and A. J. Friedhoff (1979) Enduring changes in dopamine receptor cells of pups from drug administration to pregnant and nursing rats. Science 203: 1133-1135.

Schlumpf, M., W. Lichtensteiger, W. J. Shoemaker, and F. E. Bloom (1980) Fetal monoamine systems: Early stages and cortical projections. In Biogenic Amines in Development, $\mathrm{H}$. Parvez and S. Parvez, eds., pp. 567-590, Elsevier-North Holland Publishing Co., Amsterdam.

Simmons, R. D., R. K. Miller, and C. K. Kellogg (1983) Prenatal diazepam: Distribution and metabolism in perinatal rats. Teratology, in press.

Speight, A. N. P. (1977) Floppy infant syndrome and maternal diazepam and/or nitrazepam. Lancet 2: 878 .

Vaughn, J. E., T. Sims, and N. Nakashima (1977) A comparison on the early development of axodendritic and axosomatic synapses upon embryonic mouse spinal motor neurons. J. Comp. Neurol. 175: 79-99.

Young, W. S., and M. J. Kuhar (1979) A new method for receptor autoradiography: $\left[{ }^{3} \mathrm{H}\right]$ Opioid receptors in rat brain. Brain Res. 179: 255-270.

Young, W. S., and M. J. Kuhar (1980) Radiohistochemical localization of benzodiazepine receptors in rat brain. J. Pharmacol. Fixp. Ther. 212: 337-346. 